\title{
THE FIRST UK EXPERIENCE WITH SINGLE-USE DISPOSABLE FLEXIBLE CYSTOSCOPES: AN IN-DEPTH COST ANALYSIS, SERVICE DELIVERY AND PATIENT SATISFACTION RATE WITH AMBU $®$ ASCOPETM 4 CYSTO
}

Anton Wong, Y.C. Phan, Helen Thursby, Wasim Mahmalji

Hereford County Hospital, Hereford, United Kingdom

Address for correspondence: Anton Wong: antonwong@doctors.org.uk

Received: 26 February 2021; Accepted after revision: 22 March 2021; Published: 4 April 2021.

\begin{abstract}
\section{Background and Objective}

$\mathrm{Ambu}_{\mathbb{B}}$ aScope ${ }^{\mathrm{TM}} 4$ Cysto is a single-use disposable flexible cystoscope that allows clinicians to perform the procedure at any time and any place. It simplifies workflow, frees up resources and allows clinicians to treat more patients. Our trust became the first in the UK and Europe to utilise these cystoscopes. An in-depth evaluation was performed to test its practicality, cost analysis and patient satisfaction against traditional reusable flexible cystoscopes.
\end{abstract}

\section{Material and Methods}

We compared the cost of using Ambu ${ }^{\circledR}$ aScope ${ }^{\mathrm{TM}} 4$ Cysto to perform flexible cystoscopies in 20 patients prospectively against traditional flexible cystoscopes in 20 patients retrospectively. The cost of the equipment, reprocessing, cleaning supplies and maintenance were consulted from relevant departments and companies. All prospective patients were also given a patient satisfaction questionnaire to complete. An unpaired t-test was used to analyse the data.

\section{Results}

Our study revealed that it costs $£ 135.23$ and $£ 166.33$ on average to perform a flexible cystoscopy using $\mathrm{Ambu}_{\mathbb{B}}$ aScope ${ }^{\mathrm{TM}} 4 \mathrm{Cysto}$ and the traditional flexible cystoscopes, respectively. Our patient survey revealed that there was a statistical significance between the patient experience using the single-use disposable scopes compared with the traditional reusable flexible cystoscopes $(\mathrm{P}=0.0455)$. Further, $95 \%$ of patients also preferred a single-use disposable cystoscope over traditional reusable ones, given the option.

\section{Conclusion}

Single-use disposable flexible cystoscopes are a safe and cost-efficient method of performing the procedure. It is portable and proves to be a simple, efficient and practical way of performing a flexible cystoscopy in an inpatient, outpatient, or emergency setting.

Keywords: Single-use, disposable, flexible, cystoscopes 


\section{INTRODUCTION}

Cystoscopy is an endoscopic procedure that allows for the inspection of the urinary bladder via the urethra. The origin of a cystoscope can be traced back to the early 1800s. In 1806, Phillip Bozzini designed an instrument with an elongated funnel that could be passed through an orifice. ${ }^{1}$ That instrument was used to inspect the bladder, rectum, vagina, and nasopharynx. However, the precursor to the current day cystoscope was only described in the 1870 s by Urologist such as Maximilian Carl-Friedrich Nitze and Joseph Leiter. ${ }^{2}$ In 1973, flexible fibre optic technology was applied to cystoscopy, giving rise to one of the most commonly used diagnostic tool by any Urologist, the flexible cystoscope. ${ }^{3}$

More recently, medical companies have begun to manufacture and produce single-use flexible cystoscopes, with the hope of simplifying workflow, freeing up resources, and allowing clinicians to treat more patients. ${ }^{4}$ On the 3 rd of December 2020, our trust became the first hospital in Europe to use the Ambu ${ }^{\circledR}$ aScope ${ }^{\mathrm{TM}} 4$ Cysto, a single-use disposable flexible cystoscope by Ambu ${ }^{\circledR}{ }^{5}$

The aim of our study was to evaluate and analyse the cost, service delivery and patient satisfaction on using a single-use disposable flexible cystoscope against a traditional reusable flexible cystoscope. To our knowledge, this is the first of such study in the United Kingdom and Europe.

\section{METHODS}

We compared the cost of performing flexible cystoscopies using Ambu ${ }^{\circledR}$ aScope ${ }^{\mathrm{TM}} 4$ Cysto in 20 patients prospectively with 20 patients using traditional Olympus ${ }^{\circledR}$ CYF-240 flexible cystoscopies, retrospectively.

All costs, excluding staffing cost, were accrued from sources within the endoscopy, pharmacy, and procurement departments within the hospital, and organisations which have supplied the products to our department. Some of the costs have previously been calculated for our trust. ${ }^{6}$

A patient satisfaction questionnaire (Appendix 1) was also provided to the 20 prospective patients comparing the use of the conventional Olympus ${ }^{\circledR}$ CYF-240 flexible cystoscopies to the current Ambu ${ }^{\circledR}$ aScope ${ }^{\mathrm{TM}}$ 4 Cysto. This was a 10-point Likert rating scale with point 1 being "Extremely dissatisfied" to 10 being "Extremely satisfied." The only inclusion criteria was that the patients would have had undergone a previous procedure in our department with the use of Olympus ${ }^{\circledR}$ CYF-240 video flexible cystoscopes. These patients would have had the procedure previously performed as part of their bladder cancer surveillance.

An unpaired t-test was used for statistical analysis of patient satisfaction with a statistical significance set at $\mathrm{P}<0.05$.

\section{RESULTS}

An in-depth analysis of the cost of both systems were made. Many factors were taken into consideration. These can be seen in Table 1 .

\section{CYSTOSCOPES AND MAINTENANCE}

\section{Olympus ${ }^{\circledR}$ CYF-240 video flexible cystoscopes}

Olympus ${ }^{\circledR}$ has listed that their Olympus ${ }^{\circledR}$ CYF-240 video flexible cystoscopes cost $£ 18,156$ and has an average shelf life of 7 years. In our department, we have five Olympus ${ }^{\circledR}$ CYF-240 video flexible cystoscopies and one Olympus ${ }^{\circledR}$ CYF-5 video flexible cystoscopes which cost a total of $£ 108,936$. In 2020, the service package that our department had agreed upon costs $£ 5206.00$ and $£ 3182.50$ per scope per annum for the Olympus ${ }^{\circledR}$ CYF-240 video flexible cystoscopies and the Olympus ${ }^{\circledR}$ CYF-5 video flexible cystoscopies, respectively. This amounts to £29212.50 per annum. This includes the cost of repairing these flexible cystoscopes and providing a temporary scope when required. In 2020, we have performed 699 flexible cystoscopies in total.

\section{Ambu ${ }^{\circledR}$ aScope ${ }^{\mathrm{TM}} 4$ Cysto flexible cystoscopes}

The Ambu ${ }^{\circledR}$ aScope ${ }^{\mathrm{TM}} 4$ Cysto flexible cystoscopes is a single-use disposable cystoscope that costs $£ 115$ each (Figures 1 and 2).

\section{STACKS, MAINTENANCE, AND MONITORS}

\section{Olympus ${ }^{\circledR}$ stacks}

Our department owns two Olympus ${ }^{\circledR}$ stacks, which according to Olympus ${ }^{\circledR}$ costs $£ 13,500$ each and are designed to last for an average of 7 years. These stacks are also designed to be used for bronchoscopies, 
TABLE 1 Factors for cost analysis (Reusable vs disposable cystoscopes)

\begin{tabular}{|c|c|}
\hline Olympus $^{\oplus}$ CYF-240 & Ambu $^{\oplus}$ aScope $^{\mathrm{rm}} 4$ Cysto \\
\hline Cystoscope & Disposable cystoscopes \\
\hline Cystoscope maintenance & Monitor \\
\hline Stack & Disposables \\
\hline Stack service and maintenance & Labour cost \\
\hline \multicolumn{2}{|l|}{ Reprocessing hardware } \\
\hline \multicolumn{2}{|l|}{ Reprocessing service } \\
\hline \multicolumn{2}{|l|}{ Reprocessing cost per cycle } \\
\hline \multicolumn{2}{|l|}{ Reprocessing staff cost } \\
\hline \multicolumn{2}{|l|}{ Electric and water } \\
\hline \multicolumn{2}{|l|}{ Disposables } \\
\hline Labour cost & \\
\hline
\end{tabular}

FIGURE 1. Ambu ${ }^{\circledR}$ aScope ${ }^{\mathrm{TM}} 4$ Cysto (Permission granted by $A m b u \circledR)$.

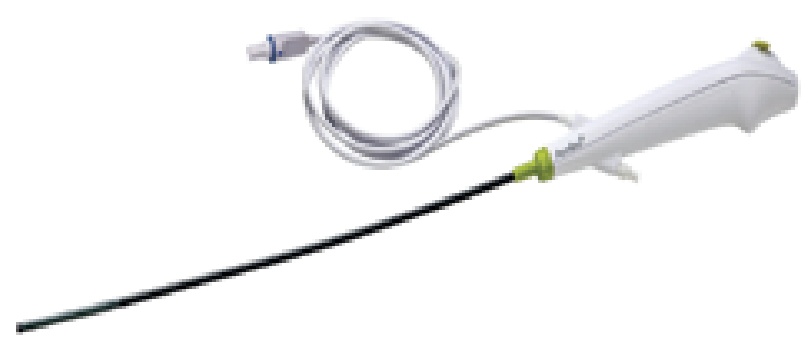

FIGURE 2. Ambu ${ }^{\circledR}$ aScope ${ }^{\mathrm{TM}} 4$ Cysto within a sterile packet (Permission granted by Ambu $\left.{ }^{\circledR}\right)$.

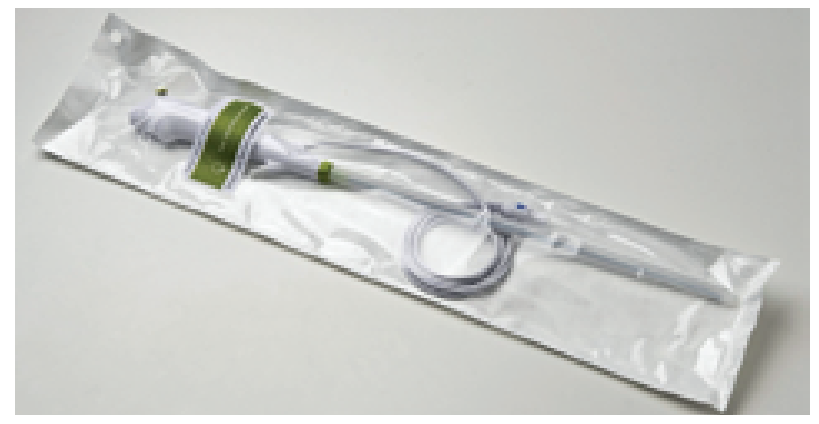

colonoscopies and oesophago-gastro-duodenoscopies, which are performed in our department. In 2020, our department paid a service package of $£ 5137.60$ for each stack and performed a total of 4963 procedures.

\section{Ambu ${ }^{\circledR}$ aView $^{\mathrm{TM}} 2$ Advance}

The Ambu ${ }^{\circledR}$ aView ${ }^{\mathrm{TM}} 2$ Advance is a high-quality, portable full-HD monitor for single-use endoscopes. According to $\mathrm{Ambu}{ }^{\circledR}$, the monitors cost $£ 4000$ each to purchase, with an 18-month guarantee. The product also has a 7-year life expectancy. However, they are given as a loan to the department until a minimum amount is spent on purchase of the scopes. For every $£ 8000$ spent (69 disposable scopes), a monitor is then given to the department. There are currently four monitors on load to our department. Between the periods of 4th of December 2020 and 29th of January, we have performed a total of 318 flexible cystoscopies using the disposable cystoscopes. Hence, we now own all four of the Ambu ${ }^{\circledR}$ aView ${ }^{\mathrm{TM}} 2$ Advance monitors (Figures 3).

\section{REPROCESSING COSTS}

\section{Reprocessing hardware}

Our department paid a total of $£ 157433.28$ for four new RAPIDAER ${ }^{\mathrm{TM}}$ Endoscope Reprocessor, $£ 53,100$ for three Getinge ${ }^{\circledR}$ (Lancer) FD8e dryer and storage cabinets, $£ 50,000$ for two reverse osmosis machines from Triple Red ${ }^{\circledR}$ (Long Crendon, UK), and $£ 56,000$ to install the two reverse osmosis machines. These kinds of hardware are also used by other endoscopes, that is, bronchoscopes, colonoscopes 
FIGURE 3. Ambu aView 2 Advance (Permission granted by Ambu®).

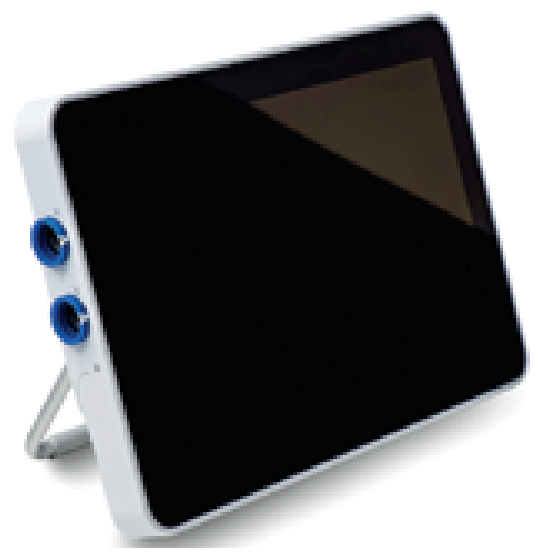

and oesophago-gastro-duodenoscopes in the department. To maintain these kinds of hardware, our department subsequently paid $£ 45137.00, £ 20336.40$, and $£ 24000.00$ per annum for the AERs, dryer and cabinets, and reverse osmosis machines, respectively.

Our department also purchased a Surestore ${ }^{\mathrm{TM}}$ Storage \& Endoscope Transport System for vacuum packing of our flexible cystoscopes, exclusively. This cost $£ 25,000$ to purchase whilst including 50 free cycles, 12 moulded trays, installation service and 12 months maintenance service. Subsequently, they cost $£ 2442$ per annum for maintenance. We also own two CleanaScope ${ }^{\circledR}$ Transport \& Short Term Storage Carts which cost $£ 1555$ each. Furthermore, we purchased SURESTORE ${ }^{\circledR}$ Supportive Tray and CleanaScope ${ }^{\circledR}$ Standard Lids which cost $£ 90$ and $£ 70$, respectively, and we currently own at least 10 of them.
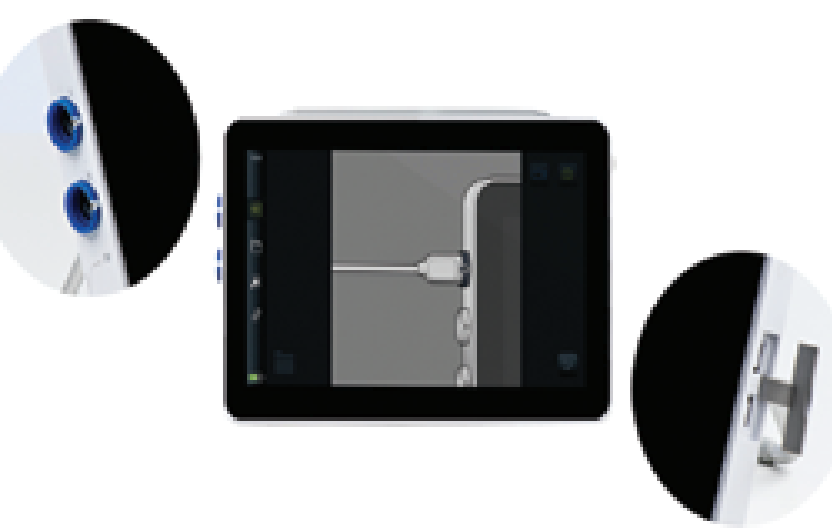

\section{Reprocessing cost per cycle}

Each of our flexible cystoscopies takes $8 \mathrm{~min}$ for washing and $17 \mathrm{~min}$ for reprocessing in the AER before it is used again. Our reprocessing department has calculated a total cost of $£ 42.50$ per scope per cycle. This cost includes reprocessing through the AER, manual cleaning, consumables used, vacuum packing, reprocessing staff cost, electricity and water.

\section{DISPOSABLES}

The cost of each disposable used for the procedure had previously been calculated for our department. ${ }^{6}$ The cost breakdown is shown in Table 2.

\section{STAFFING AND LABOUR COST}

Our flexible cystoscopy lists are usually run by a consultant or a specialty registrar, working along

TABLE 2. Breakdown of cost for each disposable item

\begin{tabular}{|l|c|c|c|}
\hline & Cost & Number used & Total cost \\
\hline Cysto pack & $£ 0.90$ & 2 & $£ 1.80$ \\
\hline Sterile gloves & $£ 0.72$ & 1 & $£ 0.72$ \\
\hline Optilube sterile lubricant & $£ 1.16$ & 1 & $£ 1.16$ \\
\hline Normal saline & $£ 0.70$ & 1 & $£ 0.70$ \\
\hline Giving set & $£ 0.48$ & 1 & $£ 0.48$ \\
\hline Adhesive aperture drape & $£ 0.68$ & 1 & $£ 0.68$ \\
\hline Chlorhexidine & $£ 0.15$ & 1 & $£ 0.15$ \\
\hline & & & $£ 5.69$ \\
\hline
\end{tabular}

J Endolum Endourol Vol 4(1):e29-e44; April 6, 2021.

This article is distributed under the terms of the Creative Commons AttributionNon Commercial 4.0 International License. (C) Wong A et al. 
with a Band 2 and a Band 5 staff. Each procedure is scheduled for $20 \mathrm{~min}$. This includes recording patients' observations, performing a urinalysis, setting up the system, consultation, and performing the procedure. An hourly rate was taken from the Royal College of Nursing (RCN) and National Health Service (NHS) employers pay scales to calculate the cost per member for our nursing staff and healthcare assistants. ${ }^{7}$ The median hourly rates for a Band 2 staff and a Band 5 staff were $£ 9.91$ and $£ 14.05$, respectively. To calculate the pay rates for specialty registrars, we used the junior doctors pay rates from the 2016 contract as listed on the British Medical Association (BMA). ${ }^{8}$ An annual salary of $£ 49,036$ was divided by 52 working weeks, working an average of $48 \mathrm{~h}$ per week using the European Working Time Directive restrictions. The labour cost for each procedure amounts to an average of $£ 14.54$.

\section{PATIENT SATISFACTION}

Our questionnaire surveyed patients' previous experience with the use of Olympus ${ }^{\circledR}$ CYF-240 video flexible cystoscopies compared with their current experience with Ambu ${ }^{\circledR}$ aScope ${ }^{\mathrm{TM}} 4$ Cysto single-use flexible cystoscopies. The mean satisfaction rate with use of reusable cystoscopes and single-use cystoscopes were 9.05 (range 6-10) and 9.65 (range 8-10), respectively. The P-value attained was 0.0455 . Further, $95 \%(\mathrm{n}=$ 19) of patients preferred to have the procedure done with a single-use flexible cystoscope whilst $5 \%(n=1)$ had no preference; $100 \%$ of patients would recommend our unit to their friends and family (Figures 4 and 5).

\section{DISCUSSION}

Single-use disposable cystoscopes offer several advantages over their reusable counterparts. These include guaranteed sterility, consistent quality, convenience and portability, with no risk of wear and tear or damage whilst eliminating the cost associated with cleaning, maintenance, repairs, and sterilisation. Currently, there are two medical companies that have introduced disposable flexible cystoscopies for diagnostic purposes, specifically the Ambu ${ }^{\circledR}$ aScope ${ }^{\mathrm{TM}}$ 4 Cysto $^{4}$ and NeoFlex-Flexible, Single-Use Cystoscope ${ }^{\mathrm{TM}} .{ }^{9}$ Coloplast ${ }^{\circledR}$ have also introduced Isiris $\alpha^{\mathrm{TM}}$, an innovative digital single use flexible cystoscope specifically for removal of ureteric stents. ${ }^{10}$
FIGURE 4. Patient experience and satisfaction score.

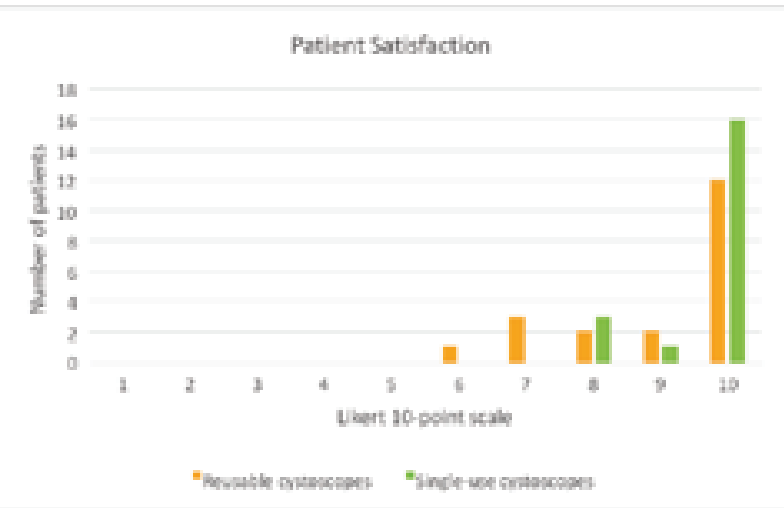

FIGURE 5. Patient preference for single-use cystoscope.
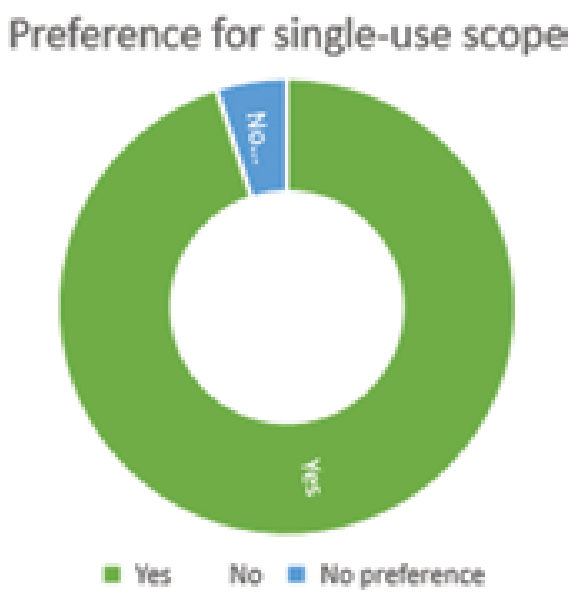

The cost effectiveness of single-use surgical instruments and endoscopes have been controversial throughout the years. ${ }^{11-14}$ However, in more recent years; medical companies are using more economical methods of producing these materials and recent studies have been more favourable towards single-use instruments. ${ }^{6,15-18}$

\section{Image quality and functionality of single-use disposable cystoscopes}

One of the most important aspects of a flexible cystoscope is the quality of the image itself, along with the specifications of the product, and whether a diagnostic investigation can be carried out satisfactorily. As aforementioned, there are currently only three disposable flexible cystoscopes in the market. As Ambu ${ }^{\circledR}$ aScope ${ }^{\mathrm{TM}} 4$ Cysto is relatively new in the market, to date we cannot find a study evaluating 
the image quality and functionality of these disposable cystoscopes. However, there are several studies evaluating the validity of single-use scopes against its reusable counterpart as a diagnostic tool.

A multi-institutional international study evaluated the use of the NeoFlex-Flexible, Single Use Cystoscope $^{\mathrm{TM}}$ against the traditional Olympus ${ }^{\circledR}$ CYF-VH flexible video cystoscopies. ${ }^{13}$ The study evaluated the performance of the cystoscope in manoeuvrability, visualisation of urological anatomy, scope deflection, image colour, illumination, and the presence of bright spots. The procedures performed included diagnostic and therapeutic procedures such as instrumentation with wires, basket, forceps, and laser. The study revealed that the single-use flexible cystoscope demonstrated a similar field of vision and visualization of anatomy, image color, and distortion. However, the image resolution was deemed inferior to the reusable flexible cystoscopes. The scope deflection of the single-use cystoscope was superior with an empty channel but had a significant drop in deflection ability upon the placement of instruments through the channel. Overall, the NeoFlex -Flexible, Single Use Cystoscope ${ }^{\mathrm{TM}}$ was said to be comparable to traditional reusable cystoscopes as it had a success rate of $96 \%$.

There have also been several studies performed to evaluate the use of Isiris $\alpha^{\mathrm{TM}}$ as a diagnostic tool and ureteric stent grasper. In 2005, a European prospective multicentre cohort study was conducted in six tertiary European reference centres to evaluate the use of Isiris $\alpha^{\mathrm{TM}}$ for double $\mathrm{J}$ stent removal, addressing success rate, image quality, deflection, manoeuvrability, and grasper functionality. ${ }^{18}$ Overall, Isiris $\alpha^{\mathrm{TM}}$ was found to display good image quality, active deflection, manoeuvrability and grasper functionality.

Seyam et al. conducted a 32 month study to evaluate the use of Isiris $\alpha^{\mathrm{TM}}$ single-use cystoscope for ureteric stent retrieval as an off-label for bladder cancer detection. ${ }^{19}$ A total of 608 and 603 procedures were performed using Storz flexible video cystoscopes and Isiris $\alpha^{\mathrm{TM}}$ integrated stent grasper, respectively. The study concluded that Isiris $\alpha^{\mathrm{TM}}$ was comparable to reusable flexible cystoscopes in detection of bladder cancer.

Talso et al. also compared the image quality, flow and flexibility of Isiris $\alpha^{\mathrm{TM}}$ against four other reusable flexible cystoscopes, Olympus ${ }^{\circledR}$ CYF-5, Olympus ${ }^{\circledR}$ CYF-VH, Storz ${ }^{\circledR} 11272 \mathrm{C} 1$, and Vision Science ${ }^{\circledR}$ CST 5000 EndoSheath. ${ }^{20}$ In a subjective analysis of image quality, Isiris a ${ }^{\mathrm{TM}}$ came second only to Olympus ${ }^{\circledR} \mathrm{CYF}$ VH. However, at $3 \mathrm{~cm}$ of distance, the field view of Isiris $\alpha^{\mathrm{TM}}$ was the narrowest. Overall, the image quality and water flow was comparable with reusable cystoscopes.

Several other studies, including our previous study have evaluated the cost effectiveness of single-use disposable flexible cystoscopes and found that single-use cystoscopes avoided delay in patient treatment, whilst saving on the cost for sterilisation, scope maintenance and repair. ${ }^{6,16,21}$

\section{$A m b u{ }^{\circledR} a S c o p e^{\mathrm{TM}} 4$ Cysto and Ambu ${ }^{\circledR}$ aView ${ }^{\mathrm{TM}} 2$ Advance}

The Ambu ${ }^{\circledR}$ aScope ${ }^{\mathrm{TM}} 4$ Cysto offers comparable specifications to traditional reusable cystoscopes. We compared the specifications against the Olympus ${ }^{\circledR}$ CYF-240 video flexible cystoscopes. The specifications are listed in Table 3.

TABLE 3 Specifications of flexible cystoscopes

\begin{tabular}{|l|l|l|}
\hline Specifications & Ambu $^{\circledR}$ aScope $^{\text {mm }}$ 4 Cysto & Olympus $^{\circ}$ CYF-240 \\
\hline Outer diameter & $16.2 \mathrm{Fr} / 5.4 \mathrm{~mm}$ & $5.3 \mathrm{~mm}$ \\
\hline Working channel & $6.6 \mathrm{Fr} / 2.2 \mathrm{~mm}$ & $2.0 \mathrm{~mm}$ \\
\hline Insertion cord length & $390 \mathrm{~mm}$ & Not specified \\
\hline Field of view & 120 degree symbol missing & 120 degree symbol missing \\
\hline Depth of field & $3-100 \mathrm{~mm}$ & Not specified \\
\hline Bending angle & $210 / 120$ degree symbol missing & $210 / 120$ degree symbol missing \\
\hline Working channel & Yes $6.6 \mathrm{Fr} / 2.2 \mathrm{~mm}$ & Yes $2.0 \mathrm{~mm}$ \\
\hline
\end{tabular}


The Ambu ${ }^{\circledR}$ aView ${ }^{\mathrm{TM}} 2$ Advance is a high quality portable full-HD monitor. ${ }^{22}$ It features full HD resolution (1920 x 1080) on 12.8 inch anti-reflective screen. All operations are simple touchscreen settings, whilst allowing you to capture live images and video recordings of the procedure, with the latter being impossible with traditional reusable cystoscopes. The images can also be transferred to the local hospital's PACS. Should a larger screen be required, it can be connected to high-quality external monitors (via HDMI or $3 \mathrm{G}-\mathrm{SDI}$ outputs). It also has a battery span of more than $3 \mathrm{~h}$ and a storage capacity of $32 \mathrm{~GB}$. The monitor itself weighs $2.7 \mathrm{~kg}$, making it portable, allowing the user to perform the procedure at any given place and time (Figure 6).

\section{Risk of damage}

The disadvantage of a reusable instrument is that is susceptible to damage along with general wear and tear. In 2020, we performed a total of 699 flexible cystoscopies using six cystoscopes but they were out of service on 13 occasions. The most common
FIGURE 6. Image quality as displayed by Ambu ${ }^{\circledR}$ aView $^{\mathrm{TM}} 2$ Advance (Permission granted by Ambu ${ }^{\circledR}$ ).

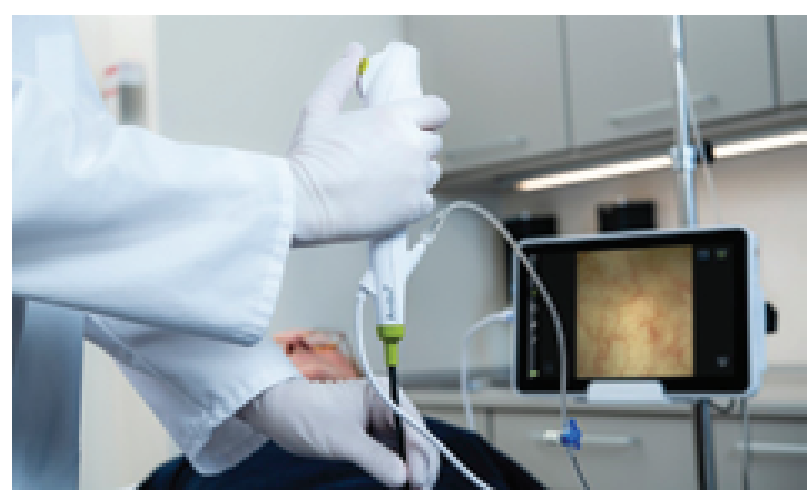

problems we encountered were leaking and staining of the glass. A detailed breakdown of the servicing schedule is listed in Table 4.

Canales et al. analysed the cost and repairs for flexible cystoscopes over a 4-year period and found that Olympus ${ }^{\circledR}$ cystoscopes appear to be durable but will still require repair every $2-3$ years. ${ }^{23}$ The most

TABLE 4 Occasions when our flexible cystoscopes were out of service

\begin{tabular}{|c|c|c|c|}
\hline Cystoscope & Year of purchase & Month & Reason \\
\hline \multirow[t]{3}{*}{ Cystoscope 1} & \multirow[t]{3}{*}{2001} & February 2020 & Chipped, leaking, delamination \\
\hline & & July 2020 & Health check \\
\hline & & August 2020 & Leaking \\
\hline \multirow[t]{3}{*}{ Cystoscope 2} & \multirow[t]{3}{*}{2001} & July 2020 & Health check \\
\hline & & July 2020 & Cracked, crushed \\
\hline & & September 2020 & Leaking \\
\hline \multirow[t]{2}{*}{ Cystoscope 3} & \multirow[t]{2}{*}{2006} & July 2020 & Health check \\
\hline & & July 2020 & Cracked, crushed \\
\hline \multirow[t]{2}{*}{ Cystoscope 4} & \multirow[t]{2}{*}{2007} & July 2020 & Health check \\
\hline & & August 2020 & Leaking, stained, delamination \\
\hline \multirow[t]{3}{*}{ Cystoscope 5} & \multirow[t]{3}{*}{2007} & January 2020 & Loose part \& uneven edge \\
\hline & & July 2020 & Health check \\
\hline & & August 2020 & Stained, crush marks \\
\hline \multirow[t]{3}{*}{ Cystoscope 6} & \multirow[t]{3}{*}{2015} & March 2020 & Health check \\
\hline & & March 2020 & Leaking \& adhesion end lifting \\
\hline & & September 2020 & Staining fluid \\
\hline
\end{tabular}


common site of damage is the distal deflection tip, more specifically the outer bending rubber. Fuselier and Mason also performed a prospective trial and reported that seven cystoscopes required replacement or repair over a 2-year period, costing them an estimated $\$ 11,500 .{ }^{24} \mathrm{McGill}$ et al. concluded that the durability of the flexible cystoscope is directly related to the optimisation of handling and storage of the scopes. Their study found an increase in procedure to failure rates from 134.6 procedure/failure to 495.4 procedure/ failure after implementing a reprocessing protocol. ${ }^{25}$ Our study found a procedure to failure rate of 53.77 in 2020. Donato et al. also performed a cost analysis for stent removal using a single-use disposable flexible cystoscope and found that the cost benefit for their department was an excess of $\$ 104,434 .^{21}$

A single-use disposable cystoscope offer the advantage of consistent quality because you get a brand new cystoscope for every procedure. It also eliminates the need for reprocessing, repairs and maintenance, allowing an increase in productivity. Patient delay due to unavailable scopes and the anxiety associated with it will be a thing of the past. Furthermore, these cystoscopes are portable and quicker to set up, allowing an improvement in workflow. In our hospital, we have increase our productivity from an average of eight procedures per session to 10 procedures per session with the use of the new single-use cystoscopes.

\section{Risk of contamination and infection}

Flexible cystoscopes undergo high level disinfection (HLD) rather than sterilisation. This is because cystoscopes are considered semicritical medical devices, which by definition are devices that come into contact with mucous membranes and non-intact skin. Whilst sterilisation eliminates all microbial life, HLD uses a chemical agent to eliminate all recognised pathogenic organisms, but not necessarily all types of microorganisms. Hence, there is always a chance of cross contamination between patients. In fact, semicritical items represent the greatest risk of disease transmission compared with critical or non-critical items. ${ }^{26}$ Several cross contaminations have been documented following endoscopic procedures. ${ }^{27}$ In 2010, Chang et al. reported an outbreak of ertapenem-resistant E. cloacae caused by a contaminated ureteroscope in 15 patients. ${ }^{28}$ Koo et al. also reported on the first outbreak of multidrug-resistant New Delhi metallo$\beta$-lactamase (NDM-1) Klebsiella in the UK, tracing the source back to the endoscopic camera head in the Urology theatre. ${ }^{29}$ In 2007, the New Mexico Department of Health reported an outbreak of Pseudomonas aeruginosa among seven patients after a cystoscopic procedure. ${ }^{30}$ Moore et al. also reported an outbreak of Pseudomonas aeruginosa amongst 143 in Exeter hospital which was subsequently traced back to a contaminated Bigelow evacuator-a suction device which was disinfected rather than sterilised. ${ }^{31}$ The first outbreak of Salmonella spp. related to the use of cystoscopes was also reported by Jimeno et al. ${ }^{32}$ Other infective outbreaks that involved urological instruments and reprocessing failures have also been documented. ${ }^{33-36}$

Flexible cystoscopy is also associated with a very small risk of urinary tract infection (UTI). The British Association of Urological Surgeons (BAUS) gives an estimate risk of UTI between one in 50 to one in 100 patients. ${ }^{37}$ This is consistent with two studies by Herr, quoting a $1.9 \%$ risk of febrile UTIs following a flexible cystoscopy. ${ }^{38,39}$

A single-use disposable scope guarantees the sterility of the instrument and eliminates any chances of cross contamination between patients. Ambu ${ }^{\circledR}$ has guaranteed that their disposable products are $100 \%$ sterile.

\section{Patient satisfaction}

Our patient satisfaction questionnaire revealed that there was a statistical significance between the patient experience using the single-use disposable scopes compared with the traditional reusable flexible cystoscopes $(\mathrm{P}=0.0455)$. Moreover, $95 \%$ of patients also preferred to have the procedure performed with a single use disposable cystoscope, given the choice.

In their study, Oderda et al. also surveyed patient experience using a disposable cystoscope for removal of ureteric stents with two specific questions, namely pain felt by the patient and the invasiveness of the procedure. ${ }^{16}$ A numeric pain rating scale (NRS) was used and revealed a median score of 0 for both pain and invasiveness felt by the patient. Similarly, Baston et al. concluded that the patient experience was enhanced with more timely removal of stents and decrease in

J Endolum Endourol Vol 4(1):e29-e44; April 6, 2021.

This article is distributed under the terms of the Creative Commons AttributionNon Commercial 4.0 International License. (c) Wong A et al. 
complication rates, although a direct measurement of patient experience was not reported. ${ }^{40}$

\section{Carbon footprint}

The production and maintenance of medical equipment can have a significant environmental impact and leave a large carbon footprint; regardless of whether they are disposable or reusable. However, very few studies have been conducted to look at the carbon footprint emitted by production of single-use disposable scopes. Recently, there has been a call for sustainability and a radical change within the endoscopy department in the midst of COVID-19 and the pandemic has shown us just how rapidly processes can change when faced with a crisis. ${ }^{41}$ The NHS is said to account for $5.4 \%$ of $\mathrm{CO} 2$ emissions in the $\mathrm{UK},{ }^{42}$ whilst the endoscopy department represents the third highest emitting hospital department. ${ }^{43}$

In 2018, Davies et al. conducted a comparative study on the environmental impact of reusable and single-use ureteroscopes. ${ }^{44}$ The comparison was done between LithovueTM (Boston Scientific) single-use digital flexible ureteroscope and Olympus Flexible Video Ureteroscope (URV-F). The study found the environmental impact for both single-use and reusable cystoscopes were comparable with a total carbon footprint lifecycle of $4.43 \mathrm{~kg}$ of $\mathrm{CO}_{2}$ and $4.47 \mathrm{~kg}$ of $\mathrm{CO}_{2}$ per case, respectively.

Sørensen et al. also conducted a comparative study on the environmental impact of reusable and singleuse bronchoscopes. ${ }^{45}$ The study compared Ambu ${ }^{\circledR}$ aScope $^{\mathrm{TM}} 4$ Broncho single-use scopes against a reusable flexible bronchoscope and found that due to the use of detergents and personal protective equipment (PPE), reusable bronchoscopes are associated with the same or a higher level of material and energy consumption as well as emissions of $\mathrm{CO}_{2}$ equivalents and resource consumption compared to the disposable scopes. However, cleaning two or more reusable scopes per set of PPE makes the impacts fairly comparable.

As Ambu ${ }^{\circledR}$ produces many single-use disposable products, they have released their statement of seeking a sustainable path for their business. In their last sustainability report, several issues were highlighted and specific sustainability targets were made. ${ }^{46}$ One of the targets that were achieved was that as of October
2020, all their manufactured products are phthalate-free. Other targets include $95 \%$ of new products released after 2025 to be PVC-free, and 100\% recyclable, reusable or compostable packaging applied by 2025 . In Malaysia, solar panels were installed on the roof of the manufacturing site, generating approximately $10 \%$ of electricity needed per year.

\section{LIMITATIONS AND FURTHER STUDY}

Several limitations have been identified in our study. Firstly, our study only included a cohort of 40 patients, which can be considered by some as a small sample size. A bigger sample size would allow us to analyse the cost effectiveness more accurately. Secondly, the cost for the reusable flexible cystoscopes may not be representative of the general costs over other years. This is because our department has performed significantly fewer flexible cystoscopies in 2020 due to the COVID-19 pandemic. Furthermore, there may be a recall bias from the patient satisfaction questionnaire as patients might have had their previous procedure performed 6-12 months ago. Finally, the environmental impact and carbon footprint with single-use cystoscopes should be evaluated further. We would recommend replicating the study with a larger sample size, in a different year and evaluating the image quality and manoeuvrability of the singleuse scopes.

\section{CONCLUSION}

An in-depth analysis was performed to analyse the practicality, cost, and patient satisfaction using a single-use disposable flexible cystoscope such as the Ambu ${ }^{\circledR}$ aScope ${ }^{\mathrm{TM}} 4$ Cysto. Overall, our study found single-use disposable flexible cystoscopes to be more cost-efficient than traditional reusable flexible cystoscopes. In addition, our patients had a better experience with the use of single-use flexible cystoscopes and would prefer their procedures to be carried out with them, given the option. Single-use disposable flexible cystoscopes offer the advantage of consistent image quality, guaranteed sterility, and increased productivity by eliminating the need for reprocessing, maintenance and repairs. The Ambu ${ }^{\circledR}$ aScope $^{\mathrm{TM}} 4$ Cysto is also user friendly, easy to set-up

J Endolum Endourol Vol 4(1):e29-e44; April 6, 2021.

This article is distributed under the terms of the Creative Commons AttributionNon Commercial 4.0 International License. (C) Wong A et al. 
and portable, allowing the procedure to be performed in an inpatient, outpatient or emergency setting. Further, studies should be carried out to evaluate the image quality and manoeuvrability and clinician satisfaction of these scopes.

\section{DISCLOSURE}

Wasim Mahmalji is a key opinion leader for Ambu.

\section{REFERENCES}

1. Shah J. Endoscopy through the ages: The history of endoscopy. BJU Int. 2002;89(7):645-52. http://dx.doi. org/10.1046/j.1464-410X.2002.02726.x

2. Samplaski MK, Jones JS. Two centuries of cystoscopy: The development of imaging, instrumentation and synergistic technologies. BJU Int. 2009;103(2):154-8. http://dx.doi.org/10.1111/j.1464-410X.2008.08244.x

3. Kennedy TJ, Preminger GM. Flexible cystoscopy. Urol Clin North Am. 1988;15(3):525-8.

4. Ambu. $\mathrm{AMBU}{ }^{\circledR} \mathrm{ASCOPE}{ }^{\mathrm{TM}} 4 \mathrm{CYSTO}$ single-use. New possibilities [Internet]. [cited 2021 Jan 30]. Available from: https://www.ambu.com/endoscopy/ urology/cystoscopes/product/ambu-ascope-4-cysto

5. Ambu_UK. Congratulations to the urology team at @ WyeValleyNHS for being the first users of the Ambu aScope 4 Cysto in the Europe! [Internet]. 2020. Available from: https://twitter.com/Ambu_UK/ status/1334440735463059456

6. Phan YC, Cobley J, Mahmalji W. Cost analysis and service delivery on using Isiris $\alpha^{\mathrm{TM}}$ to remove ureteric stents. JELEU. 2018;1(1):e3-16. http://dx.doi. org/10.22374/jeleu.v1i1.5

7. NHS Employers. NHS terms and conditions (AfC) pay scales-Hourly [Internet]. [cited 2021 Feb 16]. Available from: https://www.nhsemployers. org/pay-pensions-and-reward/nhs-terms-and-conditions-of-service---agenda-for-change/pay-scales/ hourly

8. BMA. Pay scales for junior doctors in England [Internet]. 2020 [cited $2021 \mathrm{Feb}$ 16]. Available from: https://www.bma. org.uk/pay-and-contracts/pay/junior-doctors-pay-scales/ pay-scales-for-junior-doctors-in-england

9. Neoscope. NeoFlex-Flexible, single use cystoscope ${ }^{\mathrm{TM}}$ [Internet]. [cited 2021 Jan 30]. Available from: https:// neoscope2020.com/?portfolio=flexible-cystoscope
10. Coloplast. Isiris ${ }^{\circledR}$ innovative digital single use solution for stent removal in adults [Internet]. [cited 2021 Jan 30]. Available from: https:// www.coloplast.co.uk/ isiris-en-gb.aspx

11. Bourguignon C, Destrumelle A-S, Koch S, Grumblat A, Carayon P, Chopard C, et al. Disposable versus reusable biopsy forceps in Gl endoscopy: A costminimization analysis. Gastrointest Endosc. 2003;58(2):226-9. http://dx.doi.org/10.1067/ mge. 2003.341

12. Hogan RB, Santa-Cruz R, Weeks ES, Alexander L, Hogan RB 3rd. Cost-minimization analysis of jumbo reusable forceps versus disposable forceps in a highvolume ambulatory endoscopy center. Gastrointest Endosc. 2009;69(2):284-8. http://dx.doi.org/10.1016/j. gie.2008.04.062

13. Scotland K, Wong VKF, Chan JYH, Tawfiek E, Chiura A, Chew BH, et al. Evaluation of a single-use flexible cystoscope: A multi-institutional international study. J Endourol. 2020;34(9):981-6. http://dx.doi. org/10.1089/end.2020.0002

14. Manatakis DK, Georgopoulos N. Reducing the cost of laparoscopy: Reusable versus disposable laparoscopic instruments. Minim Invasive Surg. 2014;2014:1-4. http://dx.doi.org/10.1155/2014/408171

15. Pietropaolo A, Hughes T, Tear L, Somani BK. Comparison of ureteric stent removal procedures using reusable and single-use flexible cystoscopes following ureteroscopy and lasertripsy: A micro cost analysis. Cent European J Urol. 2020;73(3):342-8. http://dx.doi. org/10.5173/ceju.2020.0159

16. Oderda M, Antolini J, Falcone M, Lacquaniti S, Fasolis G. Cost-effectiveness analysis of a singleuse digital flexible cystoscope for double $\mathrm{J}$ removal. Urologia. 2020;87(1):29-34. http://dx.doi. org/10.1177/0391560319859797

17. Butticè S, Sener TE, Netsch C, Emiliani E, Pappalardo R, Magno C. LithoVue ${ }^{\mathrm{TM}}$ : A new single-use digital flexible ureteroscope. Cent European J Urol. 2016;69(3):302-5.

18. Doizi S, Kamphuis G, Giusti G, Palmero JL, Patterson JM, Proietti S, et al. First clinical evaluation of a new single-use flexible cystoscope dedicated to double-J stent removal (Isiris ${ }^{\mathrm{TM}}$ ): A European prospective multicenter study. World J Urol. 2017;35(8):1269-75. http://dx.doi.org/10.1007/s00345-016-1986-0 
19. Seyam RM, Zeitouni OM, Alsibai TM, AlAyoub AJ, Al-Qassab OM, AlDeiry Mhd A, et al. The grasperintegrated disposable flexible cystoscope is comparable to the reusable, flexible cystoscope for the detection of bladder cancer. Sci Rep. 2020;10(1):13495. http:// dx.doi.org/10.1038/ s41598-020-70424-0

20. Talso M, Emiliani E, Baghdadi M, Orosa A, Servian $\mathrm{P}$, Barreiro A, et al. The new grasper-integrated single use flexible cystoscope for double $\mathrm{J}$ stent removal: Evaluation of image quality, flow and flexibility. World J Urol. 2017;35(8):1277-83. http:// dx.doi.org/10.1007/ s00345-016-1987-z

21. Donato P, Honore M, Zana T, Pokorny M, Bowes W, Meyer JP, et al. Prospective trial of single-use, flexible cystoscope for ureteric double-J stent removal: Cost and utility analysis. J Clin Urol. 2020;13(2):160-3. http://dx.doi.org/10.1177/2051415819860377

22. Ambu. AMBUß AVIEW ${ }^{\mathrm{TM}} 2$ ADVANCE A highquality, portable full-HD monitor for single-use endoscopy [Internet]. [cited 2020 Jan 31]. Available from: https://www.ambu.com/endoscopy/monitors/ product/ambu-aview-2-advance

23. Canales BK, Gleason JM, Hicks N, Monga M. An independent analysis of flexible cystoscope repairs and cost. J Urol. 2007;178(5):2098-101; discussion 2102. http://dx.doi.org/10.1016/j.juro.2007.07.014

24. Fuselier HA, Mason C. Liquid sterilization versus high level disinfection in the urologic office. Urology. 1997;50(3):337-40. http://dx.doi.org/10.1016/ S0090-4295(97)00218-5

25. McGill JJ, Schaeffer AJ, Gonzalez CM. Durability of flexible cystoscopes in the outpatient setting. Urology. 2013;81(5):932-7. http://dx.doi.org/10.1016/j. urology.2013.01.029

26. Rutala WA, Weber DJ. Reprocessing semicritical items: Current issues and new technologies. Am J Infect Control. 2016;44(5 Suppl):e53-62. http://dx.doi. org/10.1016/j.ajic.2015.12.029

27. Noronha AM, Brozak S. A 21st century nosocomial issue with endoscopes. BMJ. 2014;348(mar19 8):g2047-g2047. http://dx.doi.org/10.1136/bmj.g2047

28. Chang C-L, Su L-H, Lu C-M, Tai F-T, Huang Y-C, Chang $\mathrm{K}-\mathrm{K}$. Outbreak of ertapenem-resistant Enterobacter cloacae urinary tract infections due to a contaminated ureteroscope. J Hosp Infect. 2013;85(2):118-24. http:// dx.doi.org/10.1016/j.jhin.2013.06.010
29. Koo VSW, O’Neill P, Elves A. Multidrug-resistant NDM-1 Klebsiella outbreak and infection control in endoscopic urology. BJU Int. 2012;110(11 Pt C):E922-6. http://dx.doi.org/10.1111/j.1464410X.2012.11556.x

30. Wendelboe AM, Baumbach J, Blossom DB, Frank P, Srinivasan A, Sewell CM. Outbreak of cystoscopy related infections with Pseudomonas aeruginosa: New Mexico, 2007. J Urol. 2008;180(2):588-92. http:// dx.doi.org/10.1016/j.juro.2008.04.003

31. Moore B, Forman A. An outbreak of urinary Pseudomonas aeruginosa infection acquired during urological operations. Lancet. 1966;2(7470):929-31. http:// dx.doi.org/10.1016/S0140-6736(66)90535-6

32. Jimeno A, Alcalde MM, Ortiz M, Rodríguez A, Alcaraz B, Vera F. Outbreak of urinary tract infections by Salmonella spp. after cystoscopic manipulation. Actas Uroló Esp (English Edn). 2016;40(10):646-9. http://dx.doi.org/10.1016/j.acuro.2016.02.005

33. Lamas Ferreiro JL, Álvarez Otero J, González González L, Novoa Lamazares L, Arca Blanco A, Bermúdez Sanjurjo JR, et al. Pseudomonas aeruginosa urinary tract infections in hospitalized patients: Mortality and prognostic factors. PLoS One. 2017;12(5):e0178178. http://dx.doi.org/10.1371/journal.pone.0178178

34. OYong K, Coelho L, Bancroft E, Terashita D. Health care-associated infection outbreak investigations in outpatient settings, Los Angeles County, California, USA, 2000-2012. Emerg Infect Dis. 2015;21(8):1317-21. http://dx.doi.org/10.3201/eid2108.141251

35. Echols RM, Palmer DL, King RM, Long GW. Multidrugresistant Serratia marcescens bacteriuria related to urologic instrumentation. South Med J. 1984;77(2):173-7. http://dx.doi.org/10.1097/00007611-198402000-00010

36. Climo MW, Pastor A, Wong ES. An outbreak of Pseudomonas aeruginosa related to contaminated urodynamic equipment. Infect Control Hosp Epidemiol. 1997;18(7):509-10. http://dx.doi.org/10.2307/30141192

37. British Association of Urological Surgeons (BAUS). Flexible Cystoscopy [Internet]. Available from: https:// www.baus.org.uk/_userfiles/pages/files/Patients/Leaflets/Flexible\%20cystoscopy.pdf

38. Herr HW. Should antibiotics be given prior to outpatient cystoscopy? A plea to urologists to practice antibiotic stewardship. Eur Urol. 2014;65(4):839-42. http:// dx.doi.org/10.1016/j.eururo.2013.08.054 
39. Herr HW. The risk of urinary tract infection after flexible cystoscopy in patients with bladder tumor who did not receive prophylactic antibiotics. J Urol. 2015;193(2):548-51. http://dx.doi.org/10.1016/j. juro.2014.07.015

40. Baston EL, Wellum S, Bredow Z, Storey G, Palmer A, Dellen DV, et al. Office-based ureteric stent removal is achievable, improves clinical flexibility and quality of care, whilst also keeping surgeons close to their patients. Cent European J Urol. 2018;71(2):196-201.

41. Maurice JB, Siau K, Sebastian S, Ahuja N, Wesley E, Stableforth W, et al. Green endoscopy: A call for sustainability in the midst of COVID-19. Lancet Gastroenterol Hepatol. 2020;5(7):636-8. http://dx.doi. org/10.1016/S2468-1253(20)30157-6

42. Pichler P-P, Jaccard IS, Weisz U, Weisz H. International comparison of health care carbon footprints. Environ Res Lett. 2019;14(6):064004. http://dx.doi. org/10.1088/1748-9326/ab19e1
43. Vaccari M, Tudor T, Perteghella A. Costs associated with the management of waste from healthcare facilities: An analysis at national and site level. Waste Manag Res. 2018;36(1):39-47. http://dx.doi. org/10.1177/0734242X17739968

44. Davis NF, McGrath S, Quinlan M, Jack G, Lawrentschuk N, Bolton DM. Carbon footprint in flexible ureteroscopy: A comparative study on the environmental impact of reusable and single-use ureteroscopes. J Endourol. 2018;32(3):214-17. http://dx.doi.org/10.1089/ end.2018.0001

45. Lilholt Sørensen B, Grüttner H. Comparative study on environmental impacts of reusable and single-use bronchoscopes. AJEP. 2018;7(4):55. http://dx.doi. org/10.11648/j.ajep.20180704.11

46. Ambu. Sustainability report 2019/20 [Internet]. [cited 2021 Feb 16]. Available from: file://C:/Users/Anton.Wong/ Desktop/AMBU/Sustainability_Report_2019_20.pdf 
APPENDIX 1. Patient satisfaction questionnaire

\section{PATIENT QUESTIONNAIRE: SINGLE-USE, DISPOSABLE CYSTOSCOPES}

As part of your surveillance, you would likely have had a flexible cystoscopy (procedure to look into your bladder) before. We have recently started using a sterile, single-use, disposable flexible cystoscope for each patient, and would like your opinion on it.

1. Have you had this procedure performed before?

Yes/ No

2. How satisfied were you with your previous experience of this procedure?

$\begin{array}{lllllllllll}1 & 2 & 3 & 4 & 5 & 6 & 7 & 8 & 9 & 10\end{array}$

The cystoscopy is performed with a reusable cystoscope that requires sanitary process in between procedures in order to be clean and safe to use for the next patient. The sanitary process of the reusable cystoscope involves the staff cleaning the cystoscopes with chemicals.

A medical device company has developed a single-use sterile cystoscope. The single-use cystoscope is pre-sterilized in the package and used for one patient before being disposed after the procedure is completed. The performance (e.g., image quality and bending capability) of the single-use cystoscope are comparable to the regular reusable cystoscope.

Very dissatisfied

Extremely satisfied

3. Would you prefer to have the procedure performed with a single-use, sterile, disposable scope?

Yes/ No/ No preference

4. How satisfied were you with your experience today?

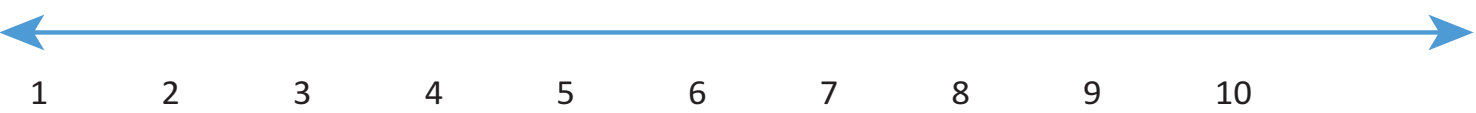

Extremely dissatisfied

Extremely satisfied

5. Would you recommend our unit to your friends and family?

Yes / No

6. Any further comments?

J Endolum Endourol Vol 4(1):e29-e44; April 6, 2021.

This article is distributed under the terms of the Creative Commons AttributionNon Commercial 4.0 International License. (c) Wong A et al. 
APPENDIX 2 Cost breakdown for $\mathrm{Ambu}^{\circledR}$ aScope ${ }^{\mathrm{TM}} 4$ Cysto

\begin{tabular}{|c|c|c|c|c|c|c|}
\hline Patient & Age & Gender & Reason for flexi & Scope cost & Disposables & Labor cost \\
\hline 1 & 78 & $\mathrm{~F}$ & Bladder cancer surveillance & $£ 115$ & $£ 5.69$ & $£ 14.54$ \\
\hline 2 & 81 & M & Bladder cancer surveillance & $£ 115$ & $\mathfrak{E 5 . 6 9}$ & $£ 14.54$ \\
\hline 3 & 64 & $\mathrm{~F}$ & Bladder cancer surveillance & $£ 115$ & $£ 5.69$ & $£ 14.54$ \\
\hline 4 & 80 & M & Bladder cancer surveillance & $£ 115$ & $£ 5.69$ & $£ 14.54$ \\
\hline 5 & 67 & $\mathrm{M}$ & Bladder cancer surveillance & $£ 115$ & $£ 5.69$ & $£ 14.54$ \\
\hline 6 & 71 & $\mathrm{~F}$ & Bladder cancer surveillance & $£ 115$ & $£ 5.69$ & $£ 14.54$ \\
\hline 7 & 81 & $\mathrm{~F}$ & Bladder cancer surveillance & $£ 115$ & $£ 5.69$ & $£ 14.54$ \\
\hline 8 & 67 & $\mathrm{M}$ & Bladder cancer surveillance & $£ 115$ & $£ 5.69$ & $£ 14.54$ \\
\hline 9 & 77 & $\mathrm{~F}$ & Bladder cancer surveillance & $£ 115$ & $£ 5.69$ & $£ 14.54$ \\
\hline 10 & 70 & $\mathrm{M}$ & Bladder cancer surveillance & $£ 115$ & $£ 5.69$ & $£ 14.54$ \\
\hline 11 & 92 & $\mathrm{~F}$ & Bladder cancer surveillance & $£ 115$ & $£ 5.69$ & $£ 14.54$ \\
\hline 12 & 73 & $\mathrm{~F}$ & Bladder cancer surveillance & $£ 115$ & $£ 5.69$ & $£ 14.54$ \\
\hline 13 & 69 & $\mathrm{M}$ & Bladder cancer surveillance & $£ 115$ & $£ 5.69$ & $£ 14.54$ \\
\hline 14 & 82 & $\mathrm{M}$ & Bladder cancer surveillance & $£ 115$ & $£ 5.69$ & $£ 14.54$ \\
\hline 15 & 83 & M & Bladder cancer surveillance & $£ 115$ & $£ 5.69$ & $£ 14.54$ \\
\hline 16 & 87 & $\mathrm{M}$ & Bladder cancer surveillance & $£ 115$ & $£ 5.69$ & $£ 14.54$ \\
\hline 17 & 69 & $\mathrm{M}$ & Bladder cancer surveillance & $£ 115$ & $£ 5.69$ & $£ 14.54$ \\
\hline 18 & 78 & $\mathrm{M}$ & Bladder cancer surveillance & $£ 115$ & $£ 5.69$ & $£ 14.54$ \\
\hline 19 & 75 & $\mathrm{~F}$ & Bladder cancer surveillance & $£ 115$ & $£ 5.69$ & $£ 14.54$ \\
\hline 20 & 73 & $\mathrm{~F}$ & Bladder cancer surveillance & $£ 115$ & $£ 5.69$ & $£ 14.54$ \\
\hline \multicolumn{6}{|c|}{ Average cost per procedure } & $\mathfrak{E 1 3 5 . 2 3}$ \\
\hline
\end{tabular}

J Endolum Endourol Vol 4(1):e29-e44; April 6, 2021.

This article is distributed under the terms of the Creative Commons AttributionNon Commercial 4.0 International License. (C) Wong A et al. 
APPENDIX 3 Cost breakdown for Olympus ${ }^{\circledR}$ CYF-240 video flexible cystoscopes

\begin{tabular}{|c|c|c|c|c|c|c|c|}
\hline Patient & Age & Gender & Reason for flexi & $\begin{array}{l}\text { Endoscope } \\
\text { Cost }\end{array}$ & Endo Service & Stack & Stack Service \\
\hline 1 & 75 & $\mathrm{M}$ & Visible haematuria & $£ 22.26$ & $£ 41.79$ & $\mathfrak{£ 0 . 7 8}$ & $£ 2.07$ \\
\hline 2 & 70 & M & Non-visible haematuria & $£ 22.26$ & $£ 41.79$ & $\mathfrak{E 0 . 7 8}$ & $£ 2.07$ \\
\hline 3 & 66 & M & Non-visible haematuria & $£ 22.26$ & $£ 41.79$ & $\mathfrak{E} 0.78$ & $£ 2.07$ \\
\hline 4 & 72 & M & Visible haematuria & $£ 22.26$ & $£ 41.79$ & $\mathfrak{E} 0.78$ & $£ 2.07$ \\
\hline 5 & 78 & $\mathrm{M}$ & Visible haematuria & $£ 22.26$ & $£ 41.79$ & $£ 0.78$ & $£ 2.07$ \\
\hline 6 & 41 & $\mathrm{M}$ & Visible haematuria & $£ 22.26$ & $£ 41.79$ & $£ 0.78$ & $£ 2.07$ \\
\hline 7 & 66 & $\mathrm{~F}$ & Recurrent UTIs & $£ 22.26$ & $£ 41.79$ & $\mathfrak{£ 0 . 7 8}$ & $£ 2.07$ \\
\hline 8 & 85 & M & Visible haematuria & $£ 22.26$ & $£ 41.79$ & $£ 0.78$ & $£ 2.07$ \\
\hline 9 & 80 & $\mathrm{M}$ & Difficult ISC/Stricture & $£ 22.26$ & $£ 41.79$ & $£ 0.78$ & $£ 2.07$ \\
\hline 10 & 70 & M & Visible haematuria & $£ 22.26$ & $£ 41.79$ & $£ 0.78$ & $£ 2.07$ \\
\hline 11 & 77 & $\mathrm{M}$ & Visible haematuria & $£ 22.26$ & $£ 41.79$ & $£ 0.78$ & $£ 2.07$ \\
\hline 12 & 69 & $\mathrm{~F}$ & Bladder cancer surveillance & $£ 22.26$ & $£ 41.79$ & $\mathfrak{£ 0 . 7 8}$ & $£ 2.07$ \\
\hline 13 & 74 & $\mathrm{~F}$ & Bladder cancer surveillance & $£ 22.26$ & $£ 41.79$ & $£ 0.78$ & $£ 2.07$ \\
\hline 14 & 76 & M & Bladder cancer surveillance & $£ 22.26$ & $£ 41.79$ & $£ 0.78$ & $£ 2.07$ \\
\hline 15 & 79 & M & Bladder cancer surveillance & $£ 22.26$ & $£ 41.79$ & $£ 0.78$ & $£ 2.07$ \\
\hline 16 & 83 & M & Bladder cancer surveillance & $£ 22.26$ & $£ 41.79$ & $£ 0.78$ & $£ 2.07$ \\
\hline 17 & 67 & $\mathrm{~F}$ & Bladder cancer surveillance & $£ 22.26$ & $£ 41.79$ & $£ 0.78$ & $£ 2.07$ \\
\hline 18 & 38 & M & Bladder cancer surveillance & $£ 22.26$ & $£ 41.79$ & $£ 0.78$ & $£ 2.07$ \\
\hline 19 & 54 & M & Bladder cancer surveillance & $£ 22.26$ & $£ 41.79$ & $£ 0.78$ & $£ 2.07$ \\
\hline 20 & 75 & M & $\begin{array}{l}\text { Lower Urinary Tract } \\
\text { Symptoms }\end{array}$ & $£ 22.26$ & $£ 41.79$ & $£ 0.78$ & $£ 2.07$ \\
\hline
\end{tabular}




\begin{tabular}{|c|c|c|c|c|c|}
\hline Patient & $\begin{array}{l}\text { Reprocessing } \\
\text { Hardware }\end{array}$ & $\begin{array}{c}\text { Reprocessing } \\
\text { Service }\end{array}$ & $\begin{array}{l}\text { Reprocessing per } \\
\text { cycle }\end{array}$ & Disposables & Labour Cost \\
\hline 1 & $£ 15.18$ & $£ 21.52$ & $£ 42.50$ & $£ 5.69$ & $£ 14.54$ \\
\hline 2 & $£ 15.18$ & $£ 21.52$ & $£ 42.50$ & $£ 5.69$ & $£ 14.54$ \\
\hline 3 & $£ 15.18$ & $£ 21.52$ & $£ 42.50$ & $£ 5.69$ & $£ 14.54$ \\
\hline 4 & $£ 15.18$ & $£ 21.52$ & $£ 42.50$ & $£ 5.69$ & $£ 14.54$ \\
\hline 5 & $£ 15.18$ & $£ 21.52$ & $£ 42.50$ & $£ 5.69$ & $£ 14.54$ \\
\hline 6 & $£ 15.18$ & $£ 21.52$ & $£ 42.50$ & $£ 5.69$ & $£ 14.54$ \\
\hline 7 & $£ 15.18$ & $£ 21.52$ & $£ 42.50$ & $£ 5.69$ & $£ 14.54$ \\
\hline 8 & $£ 15.18$ & $£ 21.52$ & $£ 42.50$ & $£ 5.69$ & $£ 14.54$ \\
\hline 9 & $£ 15.18$ & $£ 21.52$ & $£ 42.50$ & $£ 5.69$ & $£ 14.54$ \\
\hline 10 & $£ 15.18$ & $£ 21.52$ & $£ 42.50$ & $£ 5.69$ & $£ 14.54$ \\
\hline 11 & $£ 15.18$ & $£ 21.52$ & $£ 42.50$ & $£ 5.69$ & $£ 14.54$ \\
\hline 12 & $£ 15.18$ & $£ 21.52$ & $£ 42.50$ & $£ 5.69$ & $£ 14.54$ \\
\hline 13 & $£ 15.18$ & $£ 21.52$ & $£ 42.50$ & $£ 5.69$ & $£ 14.54$ \\
\hline 14 & $£ 15.18$ & $£ 21.52$ & $£ 42.50$ & $£ 5.69$ & $£ 14.54$ \\
\hline 15 & $£ 15.18$ & $£ 21.52$ & $£ 42.50$ & $£ 5.69$ & $£ 14.54$ \\
\hline 16 & $£ 15.18$ & $£ 21.52$ & $£ 42.50$ & $£ 5.69$ & $£ 14.54$ \\
\hline 17 & $£ 15.18$ & $£ 21.52$ & $£ 42.50$ & $£ 5.69$ & $£ 14.54$ \\
\hline 18 & $£ 15.18$ & $£ 21.52$ & $£ 42.50$ & $£ 5.69$ & $£ 14.54$ \\
\hline 19 & $£ 15.18$ & $£ 21.52$ & $£ 42.50$ & $£ 5.69$ & $£ 14.54$ \\
\hline 20 & $£ 15.18$ & $£ 21.52$ & $£ 42.50$ & $£ 5.69$ & $£ 14.54$ \\
\hline \multicolumn{5}{|c|}{ Average cost per procedure } & $£ 166.33$ \\
\hline
\end{tabular}

